\title{
Moral Education of Children: Moral Act as Artistic Activity
}

\author{
Ali. Ghasemi ${ }^{1}$, Mohsen Imani ${ }^{2 *}$, Alireza Sadeqzadeh ${ }^{3}$, Mohammad, Saeedimehr $^{4}$ \\ ${ }^{I}$ Department of Psychology and Education, Faculty of Human Science, Tarbiat Modares University, Tehran, \\ Iran.( PhD student in Philosophy of Education) \\ ${ }^{2}$ Department of Psychology and Education, Faculty of Human Science, Tarbiat Modares University, Tehran, \\ Iran.( Associate professor of philosophy of education) \\ ${ }^{3}$ Department of Psychology and Education, Faculty of Human Science, Tarbiat Modares University, Tehran, \\ Iran.( Associate professor of philosophy of education) \\ ${ }^{4}$ Department of Philosophy, Faculty of Human Science, Tarbiat Modares University, Tehran, Iran.( Professor of \\ Philosophy)
}

*Corresponding Author: Mohsen Imani, Department of Psychology and Education, Faculty of Human Science, Tarbiat Modares University, Tehran, Iran. (Associate professor of philosophy of education

\begin{abstract}
Education is the process of development of human talents and potential. It is one of the main components of civil society's survival. Education has various aspects such as physical, spiritual, social, artistic, moral... educations, among which moral education is the most important one. Concerning the moral education, we face values and concentrate on virtues. In this regard, many scholars have focused on rationality and less on other aspects of human being. However, John Dewey has a different look (aesthetic view) to moral education. Many discussions have been issued after Dewey's approach and proponents of pragmatism expanded it. In this paper, we are going to investigate this approach using an analyticaldescriptive method. Results reveals that children's moral behavior has two aesthetic aspects: 1- Behavior creation and production (artistic performance); 2- Aesthetic activity which is related to understanding and desire. Dewey believes that moral experience consists of these two aspects and actually moral experience is an aesthetic-artistic experience whose application in education and specifically in moral education would lead to development of sensitivity, empathy, understanding and moral practice in children.
\end{abstract}

Keywords: Moral education, Children, Moral act.

\section{INTRODUCTION}

Ethics and the related issues are among the most ancient concerns of human being. Since Socrates era, many approaches have been expressed in this regard, and many discussions have been waged about the correct moral education; but most of classic approaches concerning the moral education including those of Socrates, Aristotle, Kant, Mill, etc. have emphasized on moral education and less on other aspects of human. For instance, Aristotle believed that three factors are at work in man of virtue: nature, temper and wisdom, and that prosperity depends on coordination of the three factors. However, human perfection lies in wisdom development and wisdom is in turn the top psychological aspect and natural guide of human (kardan/2014, p24).

But new views of moral education in addition to training human rationality on developing other aspects like feelings, emotions, imagination, and so have emphasized.Schiller as a Kantian philosopher was among the earliest philosophers of the modern era who considered the relation between moral education and aesthetics, based on the modern civilization approach, which assumed it as depravity of human nature. The approach along with Rousseau's comment that "Man is born free, and everywhere he is in chain" introduced as the thinking of eighteenth century. Schiller also believes that this depravity is rooted in modern rationality, and that the intellect of modern man has deprived him from animality tools, which are condition of humanity and the prerequisite of artistic creativity. Although Schiller points the huge problem of human as Rousseau does, he never points to slogan of "back to nature"; but he attempts to reconcile modern human's rationality with his senses and instincts in order to guarantee his moral abandonment, as Kant does (Murray/2002, p281). 
Dewey like Schiller assumed that art plays an important moral role through projection and providing imagination of ideals. Dewey mention the moral imagination in education(Arneback/2014, p269) and used concepts such as experience, perfection, imagination, etc. to describe his aesthetic views toward moral education. He believes that every experience has a story and that each experience with its own design, beginning and end, has its own rhythmical movement. In fact, any non-recurring experience has a specific appearance, throughout the life. Each experience is supported by the mind reflections; and its beauty or usefulness is understood through art; and art celebrates perfection, continuously. However, it is important to Dewey that most experiences do not reach perfection in their meaning and the same is true for moral experience and also one of the important aspects of moral education knows character education (white/2015, p127; pietig/2006, p170).

In this paper, Dewey's approach toward moral act has been firstly expressed as an artistic activity. Then, moral education as well as result and application of aesthetic-artistic experience would be explained along with its component in education and specifically in moral education.

\section{Moral ACT AS ARTISTIC ACTIVITY}

Students with imaginations more naturally from mental subjects toward aesthetic and artistic experience. Moral power of art has been recognized clearly. The power is very dangerous. Art challenges the trained feelings and redeemer understanding. Lionel Trilling (1950) explains the point as follows: The most important component of moral imaginations in our life is being a new light beam (p22). Art can involve directly and really in formation of personality and moral imaginations. The most popular report of this formation is part of Plato's (Socrates') reasoning for censorship in the city, which begins with this Socrates' claim that "the gods' stories contains war, fighting or plotting against each other. They reflected badly on gods and provide poor models of gods for young people" (Ferrari/2007, p387). Socrates claims that harmony and beauty of poetry and music influence human soul and cause the formation of good moral character. In addition, lack of harmony and beauty in rhythm form bad and inappropriate personality. Based on this simple psychological reasoning, he concluded that, proper harmony and rhythm influence human soul, more than any other things; and they are actually the most powerful and successful components of virtue. So if a person is educated appropriately under the influence of music and poetry, he or she would possess a virtue personality; and if one has not such an education, he or she would have a weak personality. This example explains the art effects on the moral imaginations.

Moral activity as an artistic phenomenon is supported by the nature of our daily wise decisions. This make the role of our imaginations more clear and increases our sensitivity toward social consequences of our deeds (Dewey/1980, p272). We may be a playwright and do acting at the same time: all people are just acting throughout the life. Each individual plays many roles in his or her lifetime. Macintyre (1984) uses this metaphor and emphasizes on a process in which people are not separate symbols. Apparently, this metaphor requires dialogue, as the playwright metaphor: We are never less than those writers who narrate themselves as they live in the form of fantastic narrations ... we enter the stages and do activities, which have not been designed and constructed by ourselves. Each of us has a main character in the show belongs to ourselves. We follow others' show in some part of ours, and actually, each show restricts other ones (p219).

Individual lives are dramatic narrations that are constantly influenced from other shows. Narration of each life is part of a series of continuous narrations. We are not often rule-based and individual animals, but we are narrator of social stories. What we must perform depends on the story or stories in which we are playing some roles (Macintyre/1984, p218). When someone faces suspension in the story, asks about what will happen, then, rather than which rule is responding here? However, moral show is not pre-written by playwright. Nussbaum (1990) comments in this regard: acting means to prepare for seeing and responding each new situation which is just a scene ahead, rather than a situation as a scene in which one has to use pre-determined rules (p157).

In fact, there are many similarities between moral and artistic practice, which lead Dewey to use the metaphor of moral activity as artistic activity, in order to describe moral act. This is due to the fact that the structures of artistic and moral researches are considered similar to some experiences. They follow the structure of story or journey, which is known as "journey language" in descriptions of "Paul Ricoeur": In order to follow the journey current, one has to move forward with consideration of 
probabilities and sudden changes as well as using his or her experiences, which explain the activities in other stories... The guidance would continue until the end of journey... to understand this narration, it is necessary to understand why and how do consecutive process happen and lead to successful goals (Ricoeur/1984 p64).

The dramatic mental indecision or structured stories, which follow the form of each experience and move toward perfection, can be described as: This process has a start, middle and end points, as a journey begins and goes in a route and ends in a specific point. Each phase is qualitatively separate from others, but the process as a whole does not stop, just as incidents occurred on the perfection road (Dewey/1949 p397).

The process of experience can be compared with a traveler who moves forward. According to Dewey, the start point of human activity is an active manner against static habits that occur in the relative consistency road with environment. This distinguished quality considers a position in which a specific identity is considered as personal experience. Middle of the road is determined according to unbalanced, uncoordinated and non-compatible habits with environment, which is in fact a competition against habit and desire. This chaotic situation is essentially considered as reflective or indecision mode. The end or destination is an explorative mode or astatic feeling, which solves the problem or become close to solution. This phase is characterized by relative consistency and reintegration of desires (Fesmire/2003, p113).

Dewey believes in a similar and same principle for progress in ethics, policy, science and philosophy as good as fine arts. Every verbal description of the general characteristic of experience is a minimal description and show why Dewey's approach is so dependent on biological, technological and artistic metaphor. The moral activity metaphor as art would be clear with regard to artistic understanding as a form of social interaction; because artistic and aesthetic experience reveals common characteristics of an experience as a whole. This is probably the simplest and most direct way of maintaining what is necessary for all forms of experience (Dewey/1949, p296). The fine artists are characterized in sections with skills expressiveness, creativity and perceptiveness. Such similar concepts far from community orientation are revealed among the most prominent artists. Of course, as Johnson explains: There are many primary artistic activities, which are deprived from rationality, and a primary analysis may be inspiring rather than a definitive analysis (Johnson/1981, p210).

\section{Moral Education}

The goal of aesthetic education is the cultivation of aesthetic experiences. In the broad sense, aesthetic experience is the fun element in every human experience. Thus, all forms of education can be considered various aspects of aesthetic education. Means of precise and clear, aesthetic experiences, experiences that with what is generally considered works of art, linked (Elias, 1995, p56).

As John Dewey classical traditions challenged the nature of intellectual and moral education, the role of aesthetic in education is also critical thought and offered new. Dewey in the field with common criticism of the Greek classical tradition. Dewey completely accurate differentiation between the theoretical and the practical and contempt of Greeks oppose the action. According to Dewey, the Greeks with contempt practical matters were underestimated value of human experience. Although Plato's view all the arts lower than ideal forms ,but Aristotle's view inferior knew practical arts. It was the highest difficulty wisdom observed. According to Dewey, the practical and aesthetic activity was controlled by thought. Dewey between the intellectual, aesthetic, and practical closely to see. In contrast to the classical view, and stated that neither practical nor rational aesthetic enemies Affairs. Enemies include: uniformity, neglect of the uncertainty, adherence to the contract for operation and rational procedures. Strict abstinence, mandatory compliance And dependence on the one hand and fragmentation, disintegration and extremism in vain on the other hand, are deviations that are the opposite of integration experience. (Dewey, 1980, p40).

$\mathrm{He}$ in about the artistic experience believes that the depth and scope of meaning in the experiences reveal that may be superficial and banal from another perspective, this means that they are complete insight tool. In addition, most perfect level, it focuses perfectly good elements to offer, from the 
perspective of scattered and incomplete. They chose enjoyable elements and emphasized that every experience makes straight enjoyable. They are not Entertainment items for education But also a strong statement are that are the educational value (Dewey, 1916, p218).

Dewey also realized a more compact means for aesthetics that the artwork as the final product. But insisted that activities of artists should be seen in connection with the activities of any other person. Therefore, in his opinion a work of art, purely physical sculpture, painting, composing music is not; but in addition, it is the physical experience of the work of art as well. So that a work of art, each time you experienced in terms of aesthetics, it is the re-creation. Concepts and values that are expressed through a work of art can be experienced again. This view of art emphasizes on the power to declare a work of art and also to interact.

Dewey (1909) believes that in order to organize and control children's moral personality, we have to guide them towards two general directions: rational and aesthetic direction, we must provide the children with ability and power of judgment. Student should distinguish well from bad right from wrong. It is obvious that acquiring knowledge and information would not lead to correct judgment. According to Dewey, to enable students in judgment, we must connect education materials with their practical benefits (p32). Good and correct judgment is one aspect of useful values. A person who judges possesses measurement power to evaluate a situation $\mathrm{He}$ can understand his previous position and ignore all meaningless and inappropriate things. So far, we have stated that a person should acquire judgment power, which means attention to rational aspect of personality power. However, the fact is that awareness of the goals and their realization cannot simply be limited to the rational aspect. There is even difference between judgment power and its execution. One may possess judgment power, but he or she cannot act based on the judgment. In this case, individual needs to overcome the barriers of practical judgment, and requires to a subtle response in dealing with the issues. This response is simply aesthetic reaction, since judgment is not possible without such subtle response. By the way, individuals' power should be considered based on rationality and aesthetic aspects. The reason for differences between people is their various subtle emotional responses to the issues.

The aesthetic aspect of the moral behavior is considerable from two viewpoints: 1- production and creation of behavior (artistic performance); 2- aesthetic activity which is related to understanding and desire. Therefore, Dewey believes that moral experience consists of the two above-mentioned aspects and in fact, it is an artistic-aesthetic experience (Fesmire/2003, p78).

According to Dewey (1980), for from ambitious and artificial ideals, what is educated in moral art has happened earlier (p80). Mutual influence of man and environment depends on recognition of aesthetic and artistic performances. Dewey differentiates those artistic performances which primarily point to production of behavior and secondly those aesthetic activities which are related to understanding and desire. Moral experience is a combination of the both. This difference helps us explain restricting factors, practically. Experiences are stop in a short time during their progress, so that the strong and inclusive goals of cognition disappear. An imbalance in both sides impairs understanding and fragments or destroys it by wrong and limited meaning.

Aesthetics is not just a mental phenomenon, but it is a natural habit of daily experiencing. The same is true in art includes: (a) opening up the situation where we are; and (b) world affairs that appear in this position. Its unique quality is noticed (by meanings) when the terms are made along with environment. They appear during the usual life. Therefore, it is not created by a formulated art monopoly (Dewey/1980, p23).

The result and usage of artistic-aesthetic experience and the related components are efficient in education, specifically in moral education. This usage has four aspects: 1- sensitivity, 2- empathy, 3moral understanding, 4- moral activity.

\section{SENSITIVITY}

It contains special meanings in education. Sensitivity is a moral habit by which moral agents meet the needs of the society. Sensitivity leads to division of emotions and needs among people through dialogue and mental image. It is inferred directly by experience. Therefore, the necessary real scenarios are completed for moral understanding and moral image. Then, in a short time, emotional foundation is formed to link people in groups. Sensitivity is rooted in mutual relations and 
organizations between people and their environment. Individuals who from community consider sensitivity as eagerness to know each other's emotional and mental positions, which are in fact their situation in pains, suffering and hops for better social situations.

Sensitivity means balancing the two extremes feeling which asks moral agents to be open-minded receivers of formation. In addition, they should have a huge image of their community and life meaning. Sensitivity requires that people select information and pick their way according to a predetermined framework. Modeling and condensation are enemies of sensitivity.

\section{EMPATHY}

The main purpose of aesthetic experience is to enhance human understanding of beauty, which leads to an empathic interaction. Empathy prepare individual for cooperation in overcoming community problems. Huffman (2000) believes that empathy is the major factor in moral development and a positive motivation as well as the main source of moral behavior (p45). Dewey (1909) comments on the role of empathy in moral educations: empathy appears beyond itself and expands its domain so that it eventually approaches everyday. It also keeps the results against degradation during calculation processes. Dewey introduces knowingly empathy as a classy and top characteristic in general growth of morality. Qualitative self-consciousness leads to an empathic attitude among people. He also believes that empathy is the invigorating foundation of moral judgment (p9). It means sign in others positions through imagination and refers to immediate and sensitive response: i.e. avoiding the numb indifference and lack of motivation and incentive for moral reflection. In addition, empathy results in education of citizens characterized by development of social and political competencies, attention, attention to innovation as the key to development, and social values. This kind of education helps citizens experience the sense of being an active citizen, aesthetically.

\section{Moral Perception}

Moral perception is the capacity to comprehend such particular contexts and the uniqueness of persons. It is especially important when we need to grasp mutable, indeterminate, and vague situation in which rules and clear criteria for their application are difficult to determine. It is also allows us see not just who our students are here and now, but to see into the future and imagine their vest possibilities. (Kim/2009, p70)

Perception and empathetic connection depend of emotion and imagination. Moral perception is about recognizing and responding thoughtfully to the needs, desires, beliefs, values, and behaviors of others. Perceptions become a self-fulfilling prophecy (Rosenthal \& Rubin/1978, p 82), as we become what we love. Therefor teachers should strive to help students perceive their own and their world's perceive their own and their world's best possibilities. Assessing the best possibilities is difficult; however, it requires a great deal of imagination. On this point, imagination is the greatest instrument of the good and the most important component in the art of prophecy.

\section{MORAL ACTION}

How can we foster desire for the good? This answer can be found in Dewey's notion of no mind versus body distinction. For Dewey: the permanent element of value in the intuitional theory lies in its implicit emphasis upon the importance of direct responsiveness... Nothing can make up for the absence of immediate sensitiveness... Unless there is a direct, mainly unreflective appreciation of persons and deeds, the data for subsequent thought will be lacking or distorted. A person must feel the qualities of acts as one feels with the hands the qualities of roughness and smoothness in objects, before he has an inducement to deliberate or material with which to deliberate. Effective reflection must also terminate in a situation which is directly appreciated if thought is to be effective in action. (Dewey/1909, p268). In this passage, Dewey implies how sensitivity functions in moral education, and it's not until the qualities are felt that moral thought can be effective in moral action. For Dewey, all inquiry, not just moral inquiry, begins and ends with an affective intuition that involves a distinct feeling for the quality of a situation. Embodies reason - thought with feeling - ends up as moral action. (Kim/2009, p71) 
Students acquire knowledge or understand, not by being taught moral rules or virtues, but by being familiar with objects - whether they be objects in nature or other human being. Rather than descending from given virtues to real lives, student's moral understanding is ascending naturally to moral reasoning after observing and experiencing personally concrete and actual events in their own lives.

\section{DISCUSSION AND CONCLUSION}

This paper tries to investigate moral education from a different and unprecedented viewpoint, i.e. aesthetic approach. During centuries, the purpose of education and improve human intellectual and rational dimension, and careful thinkers attempted to consider all aspects of rational education, precisely. However, moral education has other dimensions, including aesthetic, emotions and imagination, which must be considered beside rational aspect. This paper emphasized on the aesthetic aspects from the viewpoint of Dewey.

Dewey uses the metaphor "Journey" to describe moral experience. The start point of human activity is an active manner against static habits that occur in the relative consistency road with environment. This distinguished quality considers a position in which a specific identity is considered as personal experience. Middle of the road is determined according to unbalanced, uncoordinated habits noncompatible with environment, which is in fact a competition against habit and desire. This chaotic situation is essentially considered as reflective or indecision mode. The end or destination is an explorative mode or astatic feeling, which solves the problem or become close to solution. This phase is characterized by relative consistency and reintegration of desires. He believes that in order to organize and control children's moral personality, we have to guide them towards two general directions: rational and aesthetic directions. We must provide the children with ability and power of judgment. Student should distinguish well from bad and right from wrong. It is obvious that acquiring knowledge and information would not lead to correct judgment. According to Dewey, to enable students in judgment, we must connect education materials with their practical benefits. The other dimension of moral behavior is aesthetic aspect. Dewey believes that children's moral behavior has two aesthetic aspects: 1- Behavior creation and production (artistic performance); 2- Aesthetic activity, which is related to understanding and desire. Dewey believes that moral experience consists of these two aspects and actually moral experience is an aesthetic-artistic experience whose application in education and specifically in moral education would lead to development of sensitivity, empathy, understanding and moral practice in children.

\section{REFERENCES}

[1] Arneback, E. (2014). moral imagination in education: a deweyan proposal for teachers responding to speech. Journal of moral education. P269-281.

[2] Dewey, J. (1909). Moral Principles in education. New York: Houghton Mifflin Company.

[3] Dewey, J. (1980). Art as experience. In J.A. Boylston (Ed). John Dewey: the later works, vol10. Carbondale and Edwardsville: Southern Illinois University Press.

[4] Dewey, J \&Arthur, B. (1949). Knowing and the Known. Beacon Press, Boston.

[5] Elias, J. (1995) The philosophy of Education. Classical and contemporary Krieger.

[6] Fesmire, S. (2003). John Dewey and Moral imagination: Pragmatism in Ethics. Bloomington: Indiana University Press.

[7] Ferrari, G.R.F. (2007). The Cambridge Companion to Plato’s Republic. Cambridge: Cambridge University Press.

[8] Johnson, M. (1981). Introduction. In Philosophical Perspectives on Metaphor, Ed. University of Minnesota press.

[9] Hoffman, M. L. (2000). Empathy and Moral Development: Implications for Caring and Justice. New York: Cambridge University Press.

[10] Kim, J. (2009). Dewey's Aesthetics and Today's Moral Education. Education and Culture: 96-75.

[11] MacIntyre, A. (1984). After Virtue. $2^{\text {nd }}$ ed. Notre Dame: University of Notre Dame Press.

[12] Murray, C. (2002). Key Writers on Art: The Twentieth Century (Routledge Key Guides).

[13] Nussbaum, M. (1990). Love's Knowledge. Oxford: Oxford University Press. 
[14] Pietig, J. (2006). john Dewey and character education. Journal of moral education. P170-180.

[15] Ricoeur, P. (1984). Time and Narrative. Trans: K. Mclaughlina and D. Pellaure. Chicago: University of Chicago Press.

[16] Rosenthal, R, and Donald B.Rubin. (1978). Summarizing 345 Studies of Interpersonal Expectancy Effects. In Qualitative Assessment of Research Domains: New Directions of Methodology of Social and Behavioral Sciences, 79-95

[17] Trilling, L. (1950). the Liberal Imagination. New York: Charles Scribners.

[18] White, B. (2015). scapegoat: john Dewey and character education crisis. Journal of moral education. P127144.

Citation: Ali. Ghasemi, et al. "Moral Education of Children: Moral Act as Artistic Activity " International Journal of Humanities Social Sciences and Education (IJHSSE), vol 4, no. 11, 2017, pp. 128-134. doi: http://dx.doi.org/10.20431/2349-0381.0411014.

Copyright: (C) 2017 Authors. This is an open-access article distributed under the terms of the Creative Commons Attribution License, which permits unrestricted use, distribution, and reproduction in any medium, provided the original author and source are credited. 